\title{
The Effect of Multimorbidity Patterns and the Impact of Comorbid Anxiety and Depression on Primary Health Service Use: The Men Androgen Inflammation Lifestyle Environment and Stress (MAILES) Study
}

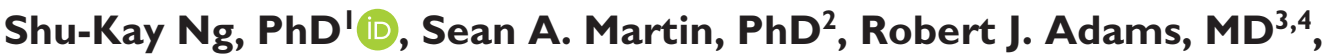 \\ Peter O'Loughlin, PhD ${ }^{2,5}$, and Gary A. Wittert, MD ${ }^{2}$
}

\begin{abstract}
This study sought to determine patterns of multimorbidity and quantify their impact on use of primary health services in the presence and absence of anxiety and depression among a cohort of urban community-dwelling men in Australia. The analytic sample consisted of men $(n=2039$; age 38-85) from the follow-up wave of a prospective cohort study of all participants of the Florey Adelaide Male Ageing Study (FAMAS; Stage 2 [2007-2010]) and age-matched men from the North-West Adelaide Health Study (NWAHS; Stage 3 [2008-2010]). Self-reported data and linkage with a national universal health coverage scheme (Medicare) provided information on the prevalence of eight chronic conditions and health service utilization information (including annual GP visits). Obesity and cardiovascular disease (CVD) were associated with the highest number of comorbid conditions. Two nonrandom multimorbidity "clusters" emerged: "CVD, Obesity, Diabetes" and "CVD, Obesity, Osteoarthritis." Participants with conditions comorbid with CVD were more likely to have 10 or more annual GP visits, compared to multimorbidity involving other conditions. In comparison to participants without CVD, the presence of CVD increased the chance of having 10 or more annual GP visits (adjusted risk ratio: $3.7 ; 95 \% \mathrm{Cl}[2.8,4.8])$. When CVD was comorbid with anxiety and depression, having 10 or more annual GP visits was more common (adjusted risk ratio: $1.8 ; 95 \% \mathrm{Cl}[1.2,2.5]$ ). Multimorbidity patterns involving CVD, especially for multimorbidity that includes CVD with comorbid anxiety and depression, should be considered in developing clinical trials to better inform medical decision-making and care for patients with CVD and comorbid conditions.
\end{abstract}

\section{Keywords}

multimorbidity, primary health services use, anxiety, depression, cardiovascular disease, cohort studies, men's health

Received April 28, 2020; revised August 25, 2020; accepted August 26, 2020

\section{Background}

Multimorbidity has recently been identified as one of the greatest challenges facing the global health system (Pearson-Stuttard et al., 2019). Estimates from the World Health Organization (WHO) demonstrate that between $40 \%$ and $60 \%$ of the adult population in developed countries have two or more chronic conditions (World Health Organization, 2016). The presence of multimorbidity has been associated with lower quality of life (Fortin et al., 2004), increased mortality (Nunes et al., 2016), and higher utilization of hospital and primary care

\footnotetext{
'School of Medicine and Menzies Health Institute Queensland, Griffith University, Nathan, Queensland, Australia

${ }^{2}$ Freemasons Centre for Male Health and Wellbeing, University of Adelaide, Adelaide, SA, Australia

${ }^{3}$ Adelaide Institute for Sleep Health, College of Medicine and Public Health, Flinders University, Bedford Park, SA, Australia

${ }^{4}$ The Health Observatory, Discipline of Medicine, University of Adelaide, The Queen Elizabeth Hospital Campus, Woodville, SA, Australia ${ }^{5}$ Chemical Pathology, SA Pathology, Adelaide, SA, Australia
}

\section{Corresponding Author:}

Shu-Kay Ng, PhD, School of Medicine, Griffith University, Room 2.4I, N78, I70 Kessels Road, Nathan, Q4I I I, Australia.

Email: s.ng@griffith.edu.au 
services (McRae et al., 2013; Salisbury et al., 2011; Westert et al., 2001; Zulman et al., 2015). Despite this, the study of multimorbidity - distinct from earlier studies that focused on comorbidity (Feinstein, 1967) - is relatively new. Multimorbidity is particularly applicable to the primary care setting, where the general practitioner (GP) tends to focus on the whole care of the patient rather than one particular condition (Harrison \& Siriwardena, 2018). In contrast to the United States, where a range of specialists provides primary care and for some conditions patients may only see a specialist (Jones et al., 2011), the Australian health-care system requires that the starting point and ongoing continuity of care is vested with GPs who are the gateway to other health-care services.

Recent editorials in Lancet (Lancet editorial, 2018), British Journal of General Practice (Mair \& Gallacher, 2017), and Journal of Comorbidity (Navickas et al., 2016) have detailed major gaps in our knowledge around multimorbidity, especially its effect on primary care services. For instance, while the prevalence of multimorbidity is known to increase with age (Singer et al., 2019), the higher number of absolute cases of multimorbidity in those aged under 65 and the limited opportunities for intervention in elderly patients have motivated a life course approach to multimorbidity in primary care (Schafer et al., 2012). Despite this, there remains an absence of studies that examine multimorbidity in younger to middle-aged cohorts (Mair \& Gallacher, 2017). The burden of comorbid mental health conditions on multimorbidity patterns, particularly anxiety and depression, has also been highlighted as requiring further study, with around one in three patients with multimorbidity having a concomitant mental health disorder (Gallo, 2017; Pearson-Stuttard et al., 2019; Rice et al., 2018). A recent U.K. Academy of Medical Sciences report (Academy of Medical Sciences, 2018) has recommended, as a research priority, the need to better understand the biopsychosocial determinants of multimorbidity clusters. However, most evidence on multimorbidity to date has been derived from large disease surveillance systems that have limited capacity to understand multimorbidity as "a non-random series of predictable clusters" (Pearson-Stuttard et al., 2019), and identify modifiable targets for intervention in primary care (Smith et al., 2016).

Given these knowledge gaps, our study involves two main objectives. The first objective is to examine the patterns of multimorbidity of eight chronic conditions (anxiety, asthma, CVD, depression, diabetes, obesity, osteoarthritis, rheumatoid arthritis). The second objective concerns studying the impact of comorbid anxiety and depression on the utilization of GP services for urban-dwelling, middle-aged to elderly men.

\section{Methods}

\section{Setting and Population}

The Men Androgen Inflammation Lifestyle Environment and Stress (MAILES) study was established in 2009 to investigate the associations of sex steroids, inflammation, and environmental and psychosocial factors with cardio-metabolic disease risk in men. The study population consisted of 2568 men aged 35-80 years at baseline from two cohort studies: all participants of the Florey Adelaide Male Ageing Study (FAMAS) and age-matched male participants of the North-West Adelaide Health Study (NWAHS). Data were collected on a number of chronic conditions as well as linked Medicare data about individual health service claims and utilization information. Medicare in Australia is a universal health insurance scheme serving all Australians for a wide range of health and hospital services. This contrasts with Medicare in the United States that primarily serves people over 65 years of age and younger disabled people and dialysis patients. All protocols were approved by the (Blinded, for review) and written, informed consent was obtained from all participants. Detailed information on recruitment and follow-up process is reported elsewhere (Grant et al., 2014). The data in the MAILES Stage 2 study contained 2039 men (FAMAS Stage 2: 2007-2010; NWAHS Stage 3: 2008-2010), representing data collected at clinics approximately 5 years after baseline visits in the two studies.

\section{Chronic Conditions}

Data on chronic disease status (CVD, diabetes, arthritis, depression, anxiety, asthma) were collected through selfreport to the question "Have you ever been told by a doctor that you have any of the following conditions?" Classification of diabetes was by self-report and biomedical measures (fasting blood glucose $\geq 7.0 \mathrm{mmol} / \mathrm{L}$ and/or HbA1c $\geq 6.5$; see Grant et al., 2014). Obesity was indicated by a waist circumference $\geq 100 \mathrm{~cm}$ as measured at the clinic visit. Depressive symptoms were assessed using the Beck Depression Inventory (BDI-Ia; Beck \& Beck, 1972) for FAMAS men and the Center for Epidemiologic Studies-Depression Scale (CES-D; Radloff, 1977) for NWAHS men. Cutoff scores of 10 and 16 for the BDI-1a and CES-D, respectively, were employed to classify into the depression categories (Yes/No). Both the BDI-1a and CES-D show comparable specificities from the classification of major depression in residential, older men (Shafer, 2006). Anxiety symptoms were assessed using the sevenitem Generalized Anxiety Disorder (GAD-7) scale (Spitzer et al., 2006). A cutoff score of 10 was used for the anxiety category (Yes/No). The GAD-7 shows good overall specificity for GAD in comparable men (Spitzer et al., 
2006). The BDI, CES-D, and GAD-7 are not formal clinical diagnostic assessments for depression or anxiety. They are screening instruments for depression or anxiety for research in the general population.

\section{Health Service Usage}

Health service use was obtained from a self-reported, piloted, health service utilization questionnaire. The number of GP visits in 1 year during the follow-up period was categorized into four categories $(0,1-4,5-9$, and $10+)$. Information was also obtained regarding participants' main reason for visiting the GP, their overall rating of the visit, whether other health issues were raised, and the use of other health service providers. GP and health utilization data were also verified through consented linkage into Medicare, the Australian Government's nationwide medical services program. There were data available on specialist or allied health consultations (including services provided by psychologists and psychiatrists). However, the number of participants who reported the use of such services is relatively small (only around 3\%), and thus such data were not considered in the analyses. This study focuses on GP services only.

\section{Demographic and Lifestyle Factors}

Age, marital status, household income, education and qualifications, work status, smoking, alcohol consumption, and physical activity were utilized as collected by selfreported questionnaires at MAILES Stage 2. Information about country of birth was taken from the baseline.

\section{Statistical Analysis}

The analysis of chronic conditions was conducted based on the clustering method of pairwise concordance statistics ( $\mathrm{Ng}$ et al., 2012), which adopts the asymmetric Somers' D statistic to quantify the degree of multimorbidity beyond chance (Ng, 2015; Ng et al., 2018). The identification of significant (nonrandom) multimorbidity between conditions, also known as "associative multimorbidity" (Prados-Torres et al., 2014), is more informative to view disease patterns for a potential sharing of risk factors of the diseases (Batstra et al., 2002; Baty et al., 2013; Ng, 2015; $\mathrm{Ng}$ et al., 2019). The clustering method adopts the Benjamini-Hochberg procedure to control for the false discovery rate at $\alpha=.05$ (Benjamini $\&$ Hochberg, 1995).

A $\chi^{2}$ analysis (for categorical variables) or analysis of variance (ANOVA; for quantitative variables) was used to test for significant differences in participants' characteristics and multimorbidity patterns between the four groups according to the number of GP visits in 1 year. A multinomial logistic regression method was adopted to assess the impact of depression and anxiety on the frequencies of GP visits via additive interaction terms, separately for obesity, CVD, and diabetes, with adjustment for participants' demographic and lifestyle characteristics. Adjusted relative risk ratios (RRRs) of GP visits relative to the reference category of 1-4 GP visits were obtained, along with their $95 \%$ confidence intervals (CIs). Predicted probabilities of $10+$ annual GP visits were calculated to illustrate the effects from either obesity, CVD, or diabetes alone as well as the impact of comorbid anxiety or depression. It is well recognized that any factor that is caused in part by the exposure (incidence of chronic condition) and is associated with outcome of interest (frequency of GP visits) should not be treated as a confounder or adjusted for in the regression analysis (Weinberg, 1993). Bias can result from adjusting for this "intermediate factor" as the estimated exposure-related risk will be markedly reduced. On the basis of literature and clinical evidence, medication was hypothesized to be part of the causal pathway between multimorbidity and GP visits; that is, multimorbidity is associated with more medications (Masnoon et al., 2017; Vogeli et al., 2007) and in turn more medications have been shown to be associated with increased health service utilization (Milton et al., 2008; Nishtala et al., 2014). Therefore, medication was not adjusted for in the multinomial logistic regression analysis.

The comparison analysis and logistic regression analysis were performed using STATA (SE 13.1; StataCorp, College Station, Texas) on the basis of 1904 participants (93.4\% of 2039) with complete information on the annual frequency of GP visits. Sensitivity analyses were conducted regarding the definitions of anxiety and depression based on either assessment instruments (GAD-7 for anxiety; BDI-1a/CES-D for depression) or medications for anxiety and/or depression, compared to the selfreported questionnaire.

\section{Results}

\section{Multimorbidity of Chronic Conditions}

Prevalence rates in decreasing order of the eight chronic conditions among the MAILES Stage 2 cohort were: obesity $(n=933$ out of $1870 ; 49.9 \%)$, diabetes ( $n=389$ of $1969 ; 19.8 \%)$, asthma ( $n=256$ of $1951 ; 13.1 \%)$, CVD $(n=235$ of $1988 ; 11.8 \%)$, osteoarthritis $(n=221$ of $1988 ; 11.1 \%)$, depression ( $n=171$ of $1865 ; 9.2 \%)$, anxiety $(n=134$ of $1865 ; 7.2 \%)$, and rheumatoid arthritis $(n=74$ of $1988 ; 3.7 \%)$. Figure 1 displays the multimorbidity patterns among these chronic conditions, along with seven pairs of conditions with significant nonrandom multimorbidity. As shown in Figure 1, obesity and CVD have the highest number of associated comorbid 


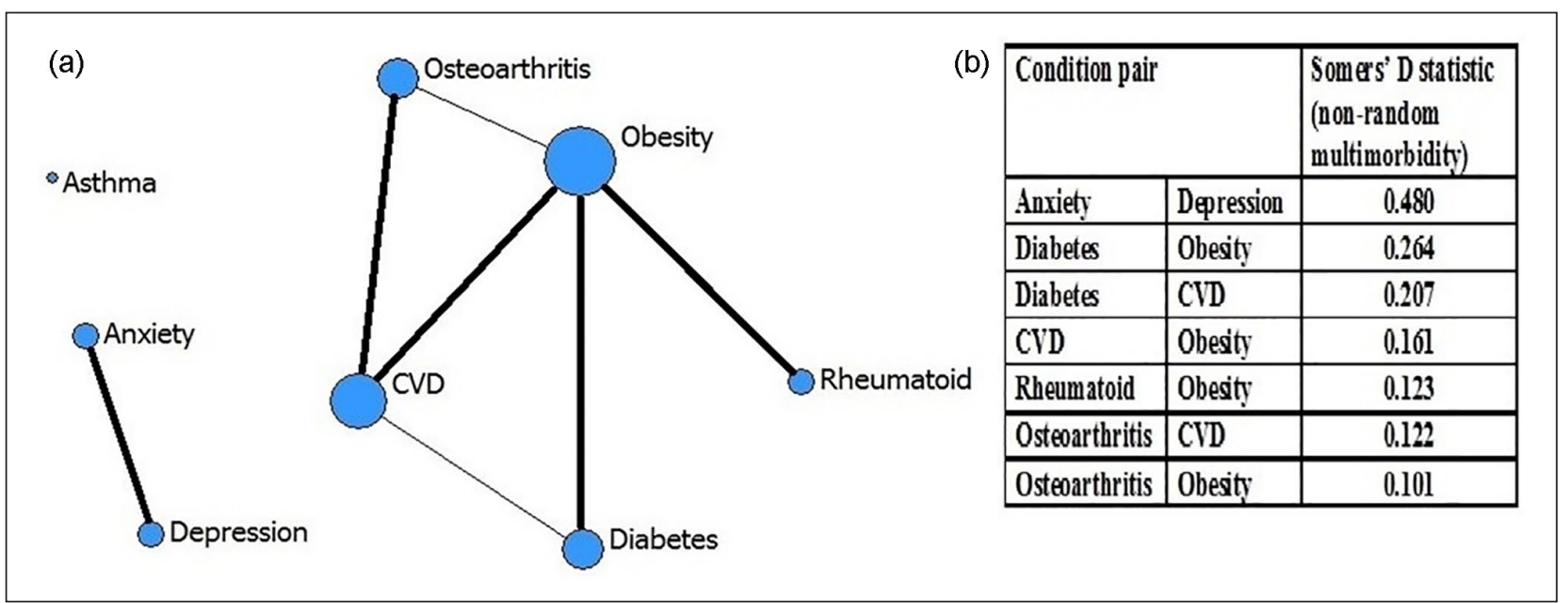

Figure I. Multimorbidity analysis. (a) Significant nonrandom multimorbidity between eight chronic conditions (nodal size is proportional to the number of conditions that are significantly comorbid with the condition; lines connect two conditions when their pairwise Somers' D statistic is significant; lines will be bolded if they represent the "closest" pairs of conditions, with which the pairwise Somers' D statistic is maximum and significant). (b) Significant comorbid chronic conditions (higher Somers' $\mathrm{D}$ statistic [maximum is I.0] represents a higher degree of nonrandom multimorbidity, where the strength of multimorbidity is measured through the number of concordant pairs indicating the presence of both conditions).

conditions. A nonrandom multimorbidity "cluster" is formed when all members are significantly associated with one another (Ng et al., 2012). Two nonrandom multimorbidity clusters were identified: "CVD, Obesity, and Diabetes" and "CVD, Obesity, and Osteoarthritis."

\section{Primary Health Service Use}

The demographic and lifestyle characteristics of all participants $(N=2039)$ and separately for participants with completed or missing information on the annual frequency of GP visits are shown in supplemental Table S1. Overall, the mean age of participants was $59.8 ; 77.8 \%$ were married; $67.0 \%$ were born in Australia; and 14.8\% had a degree. About $55.4 \%$ of participants were employed, and $36.9 \%$ were retired. Majority of participants were nonsmokers $(85.0 \%)$ and consumed less than two standard alcoholic drinks per day (79.7\%). Participants who had complete information on GP visits were more likely younger (mean age of 59.6 versus 62.6, $p=.005$ ), born in Australia $(p=.016)$, and employed $(p=.045)$. Other demographic and lifestyle characteristics were not different significantly between participants with completed or missing information on GP visits.

Among 1904 participants with GP service utilization information, $156(8.2 \%)$ did not visit a GP in the last 12 months, $1084(57.0 \%)$ visited $1-4$ times, $416(21.8 \%)$ visited 5-9 times, and 248 (13.0\%) participants had 10 or more GP visits. The median range of GP visits was 3-4 times in a year. Participants' characteristics among the four categories of GP visits are provided in Table 1. Those attending their GP more frequently tended to be older (there is a trend of increasing mean ages from 51.7 to 66.6 years, $p<.001)$. Related to this, the category of $10+$ GP visits has significantly higher proportions of people being separated/widowed $(p=.006)$, of lower income $(p<.001)$, and retired $(p<.001)$. As shown in Table 1 , it is also observed that the category of $10+$ GP visits contains significantly fewer Australian-born people $(p=.021)$ and fewer smokers $(p=.002)$. As described in the "Statistical Analysis" section, Table 1 shows the trend of increasing mean number of medications from 0.11 to $3.17(p<.001)$, indicating a positive association between medication and the frequency of GP visits. There are no differences between the four categories of GP visits in education qualification and alcohol consumption.

\section{Impact of Multimorbidity on Primary Health Service Use}

Table 2 displays the differences in nine types of comorbid conditions (identified from Figure 1) among the four categories of GP visits. From Table 2, participants with comorbid conditions have generally more GP visits compared to those without any comorbid conditions (namely, decrease in proportions of 0 GP visit and 1-4 GP visits but increase in proportions of 5-9 or 10+ GP visits; see also supplemental Figure S1). Men with comorbid conditions that include CVD were more likely to have 10 or more annual GP visits. For those participants with neither anxiety nor depression, $54.1 \%$ of participants with CVD, obesity, and diabetes; $50.0 \%$ of participants with CVD 
Table I. Demographic and Lifestyle Characteristics of Participants in the Four Categories of GP Visits $(N=1904)$.

\begin{tabular}{|c|c|c|c|c|c|}
\hline \multirow[b]{2}{*}{ Characteristics $^{\mathrm{a}}$} & \multicolumn{4}{|c|}{ Frequency $(\%)$ or Mean $(S D)$} & \multirow[b]{2}{*}{$\begin{array}{c}\text { Total } \\
(N=1904)\end{array}$} \\
\hline & $\begin{array}{c}0 \text { GP Visit } \\
(n=156) \\
(8.2 \%)\end{array}$ & $\begin{array}{c}\text { I-4 GP Visits } \\
(n=1084) \\
(57.0 \%)\end{array}$ & $\begin{array}{c}\text { 5-9 GP Visits } \\
(n=416) \\
(21.8 \%)\end{array}$ & $\begin{array}{c}\text { I0+ GP Visits } \\
(n=248) \\
(13.0 \%)\end{array}$ & \\
\hline$A g e^{b}$ & $51.7(8.3)$ & $57.8(10.9)$ & $63.2(11.2)$ & $66.6(10.6)$ & $59.6(11.5)$ \\
\hline \multicolumn{6}{|l|}{ Marital status ${ }^{b}$} \\
\hline Married & I I 8 (76.6\%) & $860(80.2 \%)$ & $315(76.6 \%)$ & 172 (69.6\%) & | 465 (77.7\%) \\
\hline Separated/widowed & $23(14.9 \%)$ & I 48 (I3.8\%) & 74 (18.0\%) & 58 (23.5\%) & $303(16.1 \%)$ \\
\hline Never married & $13(8.4 \%)$ & $65(6.1 \%)$ & $22(5.4 \%)$ & $17(6.9 \%)$ & II 7 (6.2\%) \\
\hline Missing & 2 & II & 5 & I & 19 \\
\hline \multicolumn{6}{|l|}{ Country of birth ${ }^{b}$} \\
\hline Australia & $104(66.7 \%)$ & 754 (69.6\%) & $284(68.3 \%)$ & I 46 (59.1\%) & I 288 (67.7\%) \\
\hline UK/Ireland & $27(17.3 \%)$ & $196(18.1 \%)$ & $83(20.0 \%)$ & 52 (21.1\%) & $358(18.8 \%)$ \\
\hline Europe & $18(11.5 \%)$ & 91 (8.4\%) & $38(9.1 \%)$ & 40 (16.2\%) & $187(9.8 \%)$ \\
\hline Asia/Other & 7 (4.5\%) & $43(4.0 \%)$ & II (2.6\%) & $9(3.6 \%)$ & 70 (3.7\%) \\
\hline Missing & 0 & 0 & 0 & I & I \\
\hline \multicolumn{6}{|l|}{ Household income $^{b}$} \\
\hline Up to $\$ 20 \mathrm{~K}$ & $8(5.5 \%)$ & $99(9.6 \%)$ & 74 (18.9\%) & 72 (31.7\%) & $253(14.0 \%)$ \\
\hline$\$ 20-\$ 60 \mathrm{~K}$ & $47(32.2 \%)$ & $431(41.6 \%)$ & 198 (50.5\%) & $|2|(53.3 \%)$ & $797(44.2 \%)$ \\
\hline$\$ 60-\$ 80 \mathrm{~K}$ & $26(17.8 \%)$ & $154(14.9 \%)$ & $56(14.3 \%)$ & $19(8.4 \%)$ & $255(14.2 \%)$ \\
\hline$>\$ 80 \mathrm{~K}$ & $65(44.5 \%)$ & $353(34.0 \%)$ & $64(16.3 \%)$ & $15(6.6 \%)$ & $497(27.6 \%)$ \\
\hline Missing & 10 & 47 & 24 & 21 & 102 \\
\hline \multicolumn{6}{|l|}{ Education qualification } \\
\hline High school & 39 (25.2\%) & $279(26.0 \%)$ & I 32 (31.8\%) & 79 (32.2\%) & $529(28.0 \%)$ \\
\hline Trade & $39(25.2 \%)$ & $254(23.6 \%)$ & $98(23.6 \%)$ & $6 \mathrm{I}(24.9 \%)$ & $452(23.9 \%)$ \\
\hline Cert./Diploma & $51(32.9 \%)$ & 369 (34.3\%) & $125(30.1 \%)$ & $84(34.3 \%)$ & $629(33.3 \%)$ \\
\hline Degree & $26(16.8 \%)$ & $173(16.1 \%)$ & $60(14.5 \%)$ & $21(8.6 \%)$ & $280(14.8 \%)$ \\
\hline Missing & I & 9 & I & 3 & 14 \\
\hline \multicolumn{6}{|l|}{ Work status ${ }^{\mathrm{b}}$} \\
\hline Employed & $128(83.7 \%)$ & 702 (65.1\%) & 165 (40.1\%) & $56(22.6 \%)$ & I05I (55.6\%) \\
\hline Unemployed & $5(3.3 \%)$ & $20(1.9 \%)$ & $6(1.5 \%)$ & $4(1.6 \%)$ & $35(1.9 \%)$ \\
\hline Retired & $15(9.8 \%)$ & $3 I I(28.8 \%)$ & $218(53.0 \%)$ & I 47 (59.3\%) & $691(36.6 \%)$ \\
\hline Other & $5(3.3 \%)$ & $45(4.2 \%)$ & 22 (5.4\%) & $4 \mathrm{I}(16.5 \%)$ & II 3 (6.0\%) \\
\hline Missing & 3 & 6 & 5 & 0 & 14 \\
\hline \multicolumn{6}{|l|}{ Smoking } \\
\hline Yes/Occasionally & 32 (21.1\%) & $167(16.0 \%)$ & 37 (9.3\%) & 34 (14.4\%) & $270(14.8 \%)$ \\
\hline No & 120 (78.9\%) & $876(84.0 \%)$ & $359(90.7 \%)$ & 203 (85.7\%) & I 558 (85.2\%) \\
\hline Missing & 4 & 41 & 20 & II & 76 \\
\hline \multicolumn{6}{|l|}{ Alcohol } \\
\hline$<2$ drinks & I I 8 (77.1\%) & $810(78.4 \%)$ & $315(80.4 \%)$ & 191 (84.5\%) & | 434 (79.5\%) \\
\hline 3-4 drinks & 18 (II.8\%) & 115 (II.1\%) & 45 (II.5\%) & $19(8.4 \%)$ & 197 (10.9\%) \\
\hline 5-8 drinks & $10(6.5 \%)$ & 73 (7.1\%) & $18(4.6 \%)$ & $10(4.4 \%)$ & III (6.2\%) \\
\hline$>8$ drinks & 7 (4.6\%) & $35(3.4 \%)$ & 14 (3.6\%) & $6(2.7 \%)$ & $62(3.4 \%)$ \\
\hline Missing & 3 & 51 & 24 & 22 & 100 \\
\hline Number of medications ${ }^{b}$ & $0.11(0.6)$ & $0.76(1.6)$ & $2.04(3.0)$ & $3.17(4.2)$ & $\mathrm{I} .30(2.6)$ \\
\hline
\end{tabular}

Note. GP = general practitioner.

${ }^{a}$ Differences in frequencies among the four categories were tested using $\chi^{2}$; differences in means were tested using ANOVA.

bSignificant differences among the four categories of GP visits $(p<.05)$.

and osteoarthritis; $43.8 \%$ of participants with CVD, obesity, and osteoarthritis; $42.9 \%$ of participants with CVD and diabetes; and $36.1 \%$ of participants with CVD and obesity had 10 or more annual GP visits. Table 2 also shows the increased proportions of participants with $10+$ GP visits when symptoms of anxiety or depression 
Table 2. Frequency of GP Visits for Nine Types of Comorbid Conditions.

\begin{tabular}{|c|c|c|c|c|c|}
\hline \multirow[b]{2}{*}{ Multimorbidity } & \multicolumn{4}{|c|}{ Count (Row \%) } & \multirow[b]{2}{*}{ Total } \\
\hline & $\begin{array}{c}0 \text { GP Visit } \\
n=156 \\
(8.2 \%)\end{array}$ & $\begin{array}{c}\text { I-4 GP Visits } \\
n=1084 \\
(57.0 \%)\end{array}$ & $\begin{array}{c}\text { 5-9 GP Visits } \\
n=416 \\
(21.8 \%)\end{array}$ & $\begin{array}{c}\text { I0+ GP Visits } \\
n=248 \\
(13.0 \%)\end{array}$ & \\
\hline Anxiety and depression & I (I.4\%) & $27(38.0 \%)$ & $19(26.8 \%)$ & $24(33.8 \%)$ & 71 \\
\hline Nil & $136(8.7 \%)$ & $933(59.7 \%)$ & $330(21.1 \%)$ & $163(10.4 \%)$ & 1562 \\
\hline Diabetes and obesity (anx, dep, or both) & I (2.9\%) & $9(25.7 \%)$ & $8(22.9 \%)$ & $17(48.6 \%)$ & 35 \\
\hline Diabetes and obesity (no anx or dep) & $8(4.2 \%)$ & $84(43.5 \%)$ & $55(28.5 \%)$ & $46(23.8 \%)$ & 193 \\
\hline Nil & $92(11.7 \%)$ & $505(64.0 \%)$ & $131(16.6 \%)$ & $6 \mathrm{I}(7.7 \%)$ & 789 \\
\hline Diabetes and CVD (anx, dep, or both) & $0(0 \%)$ & I (9.1\%) & $3(27.3 \%)$ & $7(63.6 \%)$ & II \\
\hline Diabetes and CVD (no anx or dep) & $0(0 \%)$ & $12(21.4 \%)$ & $20(35.7 \%)$ & 24 (42.9\%) & 56 \\
\hline Nil & $138(10.2 \%)$ & $849(62.9 \%)$ & $259(19.2 \%)$ & $103(7.6 \%)$ & 1349 \\
\hline CVD and obesity (anx, dep, or both) & I (5.6\%) & I (5.6\%) & $6(33.3 \%)$ & $10(55.6 \%)$ & 18 \\
\hline CVD and obesity (no anx or dep) & $0(0 \%)$ & $36(37.1 \%)$ & $26(26.8 \%)$ & $35(36.1 \%)$ & 97 \\
\hline Nil & $96(11.8 \%)$ & $515(63.3 \%)$ & $146(18.0 \%)$ & $56(6.9 \%)$ & 813 \\
\hline Rheumatoid arthritis and obesity (anx, dep, or both) & $0(0 \%)$ & $3(33.3 \%)$ & $2(22.2 \%)$ & $4(44.4 \%)$ & 9 \\
\hline Rheumatoid arthritis and obesity (no anx or dep) & $2(4.9 \%)$ & I 4 (45.2\%) & $9(29.0 \%)$ & $6(19.4 \%)$ & 31 \\
\hline Nil & $96(11.2 \%)$ & $531(61.9 \%)$ & $158(18.4 \%)$ & $73(8.5 \%)$ & 858 \\
\hline Osteoarthritis and CVD (anx, dep, or both) & $0(0 \%)$ & $0(0 \%)$ & I (I4.3\%) & $6(85.7 \%)$ & 7 \\
\hline Osteoarthritis and CVD (no anx or dep) & $0(0 \%)$ & $9(30.0 \%)$ & $6(20.0 \%)$ & I 5 (50.0\%) & 30 \\
\hline Nil & $148(9.7 \%)$ & $932(61.3 \%)$ & $305(20.1 \%)$ & 135 (8.9\%) & 1520 \\
\hline Osteoarthritis and obesity (anx, dep, or both) & I (6.3\%) & I (6.3\%) & 7 (43.8\%) & $7(43.8 \%)$ & 16 \\
\hline Osteoarthritis and obesity (no anx or dep) & I (I.2\%) & $40(46.0 \%)$ & $25(28.7 \%)$ & $21(24.1 \%)$ & 87 \\
\hline Nil & $94(\mathrm{II} .7 \%)$ & $503(62.5 \%)$ & $149(18.5 \%)$ & $59(7.3 \%)$ & 805 \\
\hline Diabetes, CVD, and obesity ${ }^{\mathrm{a}}$ (anx, dep, or both) & $0(0 \%)$ & $0(0 \%)$ & I (I4.3\%) & $6(85.7 \%)$ & 7 \\
\hline Diabetes, CVD, and obesitya (no anx or dep) & $0(0 \%)$ & $9(24.3 \%)$ & $8(21.6 \%)$ & $20(54.1 \%)$ & 37 \\
\hline Nil & $91(12.3 \%)$ & $482(65.2 \%)$ & $122(16.5 \%)$ & $44(6.0 \%)$ & 739 \\
\hline Osteoarthritis, CVD, and obesity (anx, dep, or both) & $0(0 \%)$ & $0(0 \%)$ & I (33.3\%) & $2(66.7 \%)$ & 3 \\
\hline Osteoarthritis, CVD, and obesity (no anx or dep) & $0(0 \%)$ & $6(37.5 \%)$ & $3(18.8 \%)$ & $7(43.8 \%)$ & 16 \\
\hline Nil & $93(12.4 \%)$ & $480(64.0 \%)$ & $130(17.3 \%)$ & $47(6.3 \%)$ & 750 \\
\hline
\end{tabular}

Note. Data are counts (row percentages) in each category of GP visits. Comparison is between participants with the specific type of comorbid conditions (split by those with comorbid anxiety and/or depression [anx, dep, or both] and those with no anxiety or depression [no anx or dep]) relative to those participants without any of the specific comorbid conditions (denoted as "Nil"); participants with either of the specific comorbid conditions were excluded from the comparisons.

Values in bold indicate the highest-frequency category of GP visits for each pattern of comorbid conditions. CVD = cardiovascular disease.

${ }^{a}$ The multimorbidity group corresponds to a multimorbidity cluster identified from Figure I.

were also present (e.g., from $54.1 \%$ to $85.7 \%$ and from $43.8 \%$ to $66.7 \%$ for participants, respectively, with "CVD, Obesity, and Diabetes" and "CVD, Obesity, and Osteoarthritis," the two nonrandom multimorbidity clusters identified).

The results of multinomial logistic regression models assessing the impact of anxiety and/or depression (defined by the self-reported questionnaire) on the frequencies of GP visits are provided in Table 3 , separately for Conditions A (obesity), B (CVD), and C (diabetes). As described in the "Methods" section, these results are based on the use of screening instruments and do not indicate formal diagnostic assessments for depression or anxiety. Besides age, household income, and work status, other demographic and lifestyle characteristics were not significant.

The presence of obesity was associated with an increase in the frequency of GP visits (adjusted RRRs: 1.4 for 5-9 GP visits and 2.3 for $10+$ GP visits over 1-4 GP visits) for participants without anxiety and depression. For participants with obesity, the presence 
Table 3. Multinomial Logistic Regression on the Four Categories of GP Visits.

\begin{tabular}{|c|c|c|c|}
\hline Characteristics & $\begin{array}{c}0 \text { GP Visit }(n=138) \\
\text { Versus I-4 } \\
\text { GP Visits }(n=952)\end{array}$ & $\begin{array}{c}\text { 5-9 GP Visits }(n=363) \\
\text { Versus I-4 } \\
\text { GP Visits }(n=952)\end{array}$ & $\begin{array}{c}10+\text { GP Visits }(n=200) \\
\text { Versus I-4 } \\
\text { GP Visits }(n=952)\end{array}$ \\
\hline \multicolumn{4}{|l|}{ Condition A (for obesity) ${ }^{\mathrm{a}}$} \\
\hline $\begin{array}{l}\text { Obesity effect for participants } \\
\text { without anx or dep }\end{array}$ & $0.7(0.5-1.1)$ & $1.4 *(1.1-1.9)$ & $2.3 *(1.5-3.5)$ \\
\hline $\begin{array}{l}\text { Extra effect from anx, dep, or both } \\
\text { for participants with obesity }\end{array}$ & $0.9(0.3-2.7)$ & $2.2 *(1.3-3.7)$ & $3.8 *(2.2-6.6)$ \\
\hline Age & $0.9 *(0.9-1.0)$ & $1.0(1.0-1.0)$ & $1 . I *(I .0-I .1)$ \\
\hline \multicolumn{4}{|l|}{ Household income } \\
\hline Up to $\$ 20 \mathrm{~K}$ & Reference & Reference & Reference \\
\hline$\$ 20-\$ 60 \mathrm{~K}$ & $0.9(0.3-2.3)$ & $0.8(0.6-1.2)$ & $0.7(0.5-1.1)$ \\
\hline$\$ 60-\$ 80 \mathrm{~K}$ & $0.9(0.3-2.7)$ & I.I (0.6-I.8) & $0.6(0.3-1.3)$ \\
\hline$>\$ 80 \mathrm{~K}$ & $1.0(0.4-2.7)$ & $0.6(0.4-1.0)$ & $0.3 *(0.1-0.6)$ \\
\hline \multicolumn{4}{|l|}{ Work status } \\
\hline Employed & Reference & Reference & Reference \\
\hline Unemployed & $1.6(0.5-5.2)$ & $0.9(0.3-2.5)$ & $1.0(0.3-3.9)$ \\
\hline Retired & $0.7(0.3-1.6)$ & $2.2 *(1.5-3.4)$ & $1.6(0.9-2.9)$ \\
\hline Other & $0.8(0.3-2.2)$ & $1.5(0.8-2.8)$ & $6.3 *(3.4-11.6)$ \\
\hline \multicolumn{4}{|l|}{ Condition B (for CVD) ${ }^{a}$} \\
\hline $\begin{array}{l}\text { CVD effect for participants without } \\
\text { anx or dep }\end{array}$ & N/A & $1.7 *(1.1-2.6)$ & $4.8 *(3.0-7.6)$ \\
\hline $\begin{array}{l}\text { Extra effect from anx, dep, or both } \\
\text { for participants with CVD }\end{array}$ & & $4.2 *(1.0-16.8)$ & $5.0 *(1.3-19.7)$ \\
\hline Age & & $1.0(1.0-1.0)$ & $1.0 *(1.0-1.1)$ \\
\hline \multicolumn{4}{|l|}{ Household income } \\
\hline Up to $\$ 20 \mathrm{~K}$ & & Reference & Reference \\
\hline$\$ 20-\$ 60 \mathrm{~K}$ & & $0.8(0.6-1.2)$ & $0.6 *(0.4-1.0)$ \\
\hline$\$ 60-\$ 80 \mathrm{~K}$ & & $1.0(0.6-1.6)$ & $0.5 *(0.3-1.0)$ \\
\hline$>\$ 80 \mathrm{~K}$ & & $0.5^{*}(0.3-0.9)$ & $0.2 *(0.1-0.5)$ \\
\hline \multicolumn{4}{|l|}{ Work status } \\
\hline Employed & & Reference & Reference \\
\hline Unemployed & & $0.8(0.3-2.3)$ & $\mathrm{I} .0(0.3-3.7)$ \\
\hline Retired & & $2.2 *(1.5-3.3)$ & $1.6(0.9-2.7)$ \\
\hline Other & & $1.5(0.8-2.7)$ & $5.8 *(3.2-10.5)$ \\
\hline \multicolumn{4}{|l|}{ Condition C (for diabetes) ${ }^{\mathrm{a}}$} \\
\hline $\begin{array}{l}\text { Diabetes effect for participants } \\
\text { without anx or dep }\end{array}$ & $0.8(0.4-1.6)$ & $1.9 *(1.4-2.7)$ & $3.1 *(2.1-4.8)$ \\
\hline $\begin{array}{l}\text { Extra effect from anx, dep, or both } \\
\text { for participants with diabetes }\end{array}$ & $1.7(0.3-8.9)$ & $1.2(0.5-2.8)$ & $3.0 *(1.3-6.8)$ \\
\hline Age & $0.9 *(0.9-1.0)$ & $1.0(1.0-1.0)$ & $I . I *(I .0-I . I)$ \\
\hline \multicolumn{4}{|l|}{ Household income } \\
\hline Up to $\$ 20 \mathrm{~K}$ & Reference & Reference & Reference \\
\hline$\$ 20-\$ 60 \mathrm{~K}$ & $0.8(0.3-2.0)$ & $0.9(0.6-1.3)$ & $0.7(0.5-1.1)$ \\
\hline$\$ 60-\$ 80 \mathrm{~K}$ & $0.8(0.3-2.3)$ & $1.0(0.6-1.8)$ & $0.6(0.3-1.3)$ \\
\hline$>\$ 80 \mathrm{~K}$ & $0.9(0.3-2.2)$ & $0.6 *(0.4-1.0)$ & $0.3 *(0.1-0.6)$ \\
\hline \multicolumn{4}{|l|}{ Work status } \\
\hline Employed & Reference & Reference & Reference \\
\hline Unemployed & $1.9(0.6-5.5)$ & $0.8(0.3-2.3)$ & $0.9(0.2-3.5)$ \\
\hline Retired & $0.7(0.3-1.6)$ & $2.1 *(1.4-3.2)$ & $1.5(0.9-2.6)$ \\
\hline Other & $0.8(0.3-2.1)$ & I.5 (0.8-2.8) & $5.8 *(3.2-10.7)$ \\
\hline
\end{tabular}

Note. Data are adjusted relative risk ratios (RRRs) with $95 \% \mathrm{Cl}$ (significant results marked with *). Extra effect refers to the interaction term of the condition and anxiety/depression; it compares the frequency of GP visits between the patients with the condition and those with the condition and anxiety/depression. N/A for Model B because there are no participants with comorbid conditions involving CVD in the category of 0 GP visit. Other work status includes student and people with home duties. CVD = cardiovascular disease. aNumber of medications was not adjusted in the models; see text for details. 
of anxiety or depression was associated with a further increase in the frequency of GP visits (adjusted RRRs: 2.2 for 5-9 GP visits and 3.8 for 10+ GP visits relative to 1-4 GP visits). The predicted probabilities of $10+$ GP visits, comparing men without obesity, anxiety, or depression to those with obesity but no anxiety or depression, and to those with obesity and anxiety, depression, or both, are displayed in Figure 2(A). The corresponding predicted probabilities of $10+$ GP visits for these three groups were $4.5 \%, 9.1 \%$, and $22.3 \%$, respectively. The adjusted risk ratio of $10+\mathrm{GP}$ visits for obesity alone was $2.0=9.1 / 4.5(95 \% \mathrm{CI}[1.5,2.8])$, whereas that attributed to anxiety or depression was $2.4=22.3 / 9.1$ (95\% CI $[1.9,3.2])$.

The presence of CVD was associated with an increase in the frequency of GP visits (adjusted RRRs: 1.7 for 5-9 GP visits and 4.8 for 10+ GP visits) for participants without anxiety and depression. For participants with CVD, the presence of anxiety or depression was associated with a further increase in the frequency of GP visits (adjusted RRRs: 4.2 for 5-9 GP visits and 5.0 for 10+ GP visits relative to $1-4$ GP visits). The predicted probabilities of $10+$ GP visits were $5.7 \%, 21.0 \%$, and $36.8 \%$ for the groups without CVD anxiety or depression, CVD without anxiety or depression, and CVD with anxiety and/or depression, respectively (Figure 2B). The adjusted risk ratio of 10+ GP visits for CVD alone was 3.7 (95\% CI $[2.8,4.8])$, whereas that attributed to anxiety or depression was 1.8 (95\% CI [1.2, 2.5]).

The presence of diabetes was associated with an increase in the frequency of GP visits (adjusted RRRs: 1.9 for 5-9 GP visits and 3.1 for 10+ GP visits) for participants without anxiety and depression. For participants with diabetes, the presence of anxiety or depression was associated with a further increase in the chance of $10+$ GP visits over 1-4 GP visits, with an adjusted RRR of 3.0. The predicted probabilities of $10+$ GP visits were $5.5 \%, 13.5 \%$, and $30.1 \%$ for the groups without diabetes, anxiety or depression, diabetes without anxiety and depression, and diabetes with anxiety and/or depression, respectively. The adjusted risk ratio of 10+ GP visits for diabetes alone was 2.4 (95\% CI [1.9, 3.2]), whereas that attributed to anxiety or depression was 2.2 (95\% CI [1.6, 3.1]) (Figure 2C).

Additional results of the sensitivity analyses on the definition of anxiety and depression based on formal clinical diagnosis (GAD-7 for anxiety; BDI-1a/CES-D for depression) or medications for anxiety and/or depression are provided in supplemental Tables S2 and S3. The results indicate the same conclusion as above that the presence of clinically diagnosed or medication-based anxiety and/or depression was significantly associated with a further increase in the chance of $10+$ GP visits.

\section{Discussion}

This study presents findings about the utilization of GP services by older-aged community-dwelling men (38-85 years) in relation to their patterns of multimorbidity, where two nonrandom multimorbidity "clusters" of "CVD, Obesity, Diabetes" and "CVD, Obesity, Osteoarthritis" were identified, as well as the impact of comorbid anxiety and depression. There is a common misperception that "men don't go to the doctors." In 2014-2015, an estimated 7.4 million males aged $\geq 15$ years $(78 \%)$ in Australia had seen a GP at least once in the previous year; the proportion increased with age (from $80.4 \%$ at age $45-54$ to $96.3 \%$ at age $\geq 65$ ). In $2013-2014$, expenditure on primary health-care and hospital services was $38 \%$ and $40 \%$, respectively, of the total health funding in Australia (Australian Institute of Health and Welfare, 2015). We previously reported that $>90 \%$ of men in our cohort attended their GP at least once in the preceding year (Wittert et al., 2011). The current study shows higher proportions of at least one GP visit in the previous year for men with comorbid conditions (e.g., $96 \%$ for men with diabetes and obesity; $100 \%$ for men with diabetes, obesity, and CVD). Specifically, this study revealed that men with chronic conditions comorbid with CVD are more likely to have 10 or more annual GP visits, compared to multimorbidity involving other conditions such as diabetes, obesity, arthritis, or depression and anxiety, in the absence of CVD. Primary health service use has previously been shown to be frequent in men with multimorbidity involving heart failure in older men (Robertson et al., 2012) or congenital heart disease in younger men (mean age 28.1 years; Billett et al., 2008). Our study quantified the impact of multimorbidity involving obesity, CVD, or diabetes on the relative risks of higher frequencies in annual GP visits, showing again higher impact from CVD compared to multimorbidity involving obesity or diabetes without CVD, after adjustment for demographic factors. Furthermore, there is a two to three-fold increase in the chance of having 10 or more GP services annually for Australian men with CVD alone.

Another significant driver of primary health-care service use among men is mental health disorders. Data from the FAMAS cohort (men aged 35-80) showed an adjusted odds ratio $(O R)$ of 3.9 of $10+$ annual GP visits versus none for depressed men (Atlantis et al., 2011). Based on a national survey (aged 16-85), approximately $27.5 \%$ of men with mental disorders made use of any services for mental health problems in a year, compared to $8.8 \%$ of the general Australian men population (Burgess et al., 2009). Our study found that $33.8 \%$ of men with anxiety and depression had 10 or more annual GP visits, compared to $10.4 \%$ of men without anxiety 


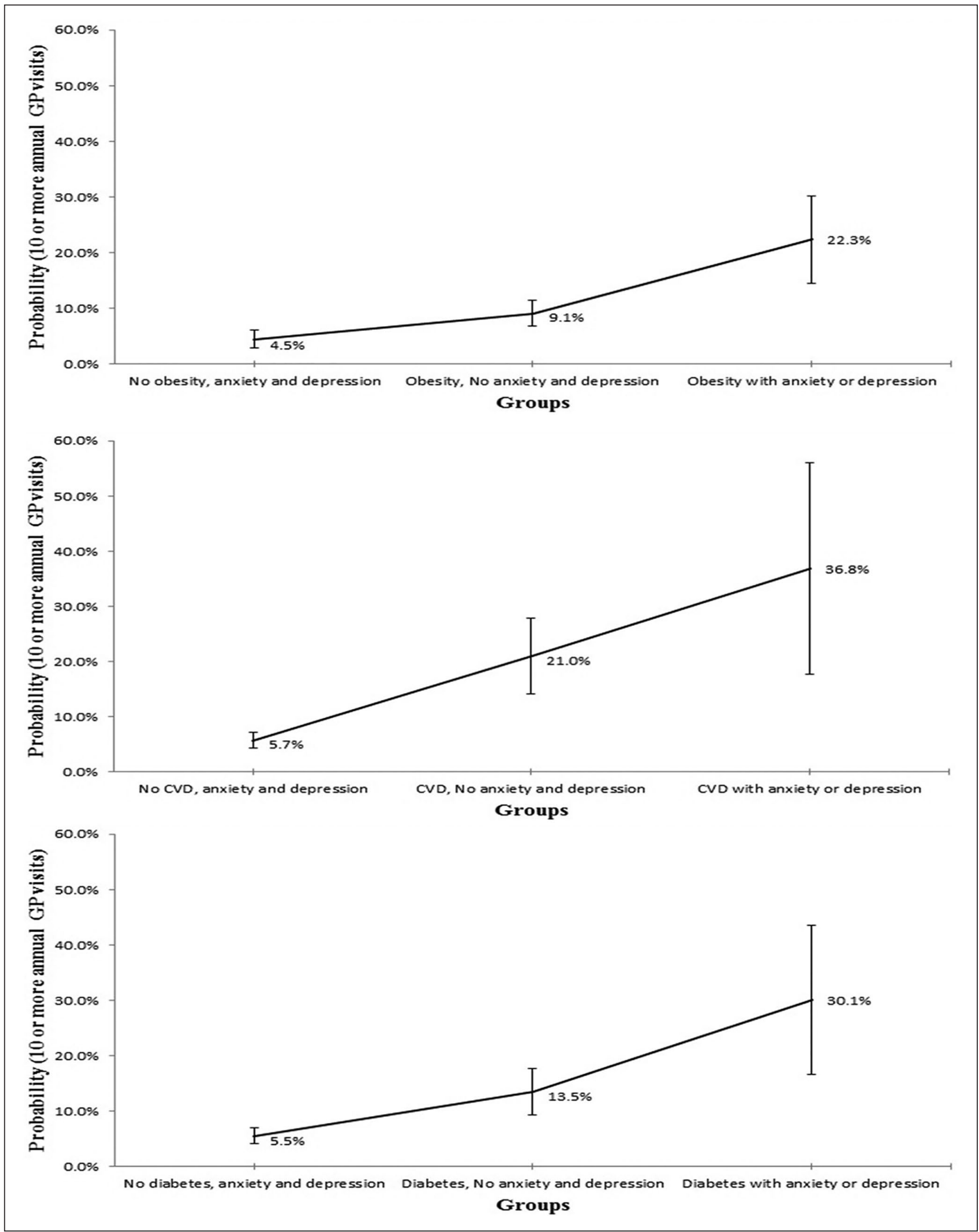

Figure 2. Adjusted predictions of 10 or more annual GP visits with $95 \% \mathrm{Cls}$ for (A) obesity, (B) CVD, and (C) diabetes conditions. CVD = cardiovascular disease. 
and depression. Primary health service use particularly in community-dwelling men with anxiety and/or depression in addition to other chronic health conditions was less researched. Without accounting for gender difference, it has been documented that comorbid depression in persons with diabetes is associated with increased health-care utilization for a Hungarian population aged $>18$ and a sample of African American patients aged $\geq 40$ (Husaini et al., 2004; Vamos et al., 2009). Our study revealed for the first time the synergistic effect of comorbid anxiety and/or depression with either obesity, CVD, or diabetes on primary health service use for older-aged men. The likelihood of having 10 or more annual GP visits increased by $140 \%, 80 \%$, and $120 \%$, respectively, for comorbid obesity, CVD, or diabetes due to anxiety and/ or depression. But the overall effect is still the largest (the predicted probability of $10+$ GP visits was $36.8 \%$ ) for anxiety and/or depression with comorbid CVD compared to obesity $(22.3 \%)$ and diabetes $(30.1 \%)$. The significance of comorbid depression and anxiety is not just a matter of increased use of primary care services (Atlantis et al., 2012; Roy-Byrne et al., 2008; Van der Kooy et al., 2007). Nabi et al. (2010) reported that depression symptoms are associated with an increased risk of all-cause death for middle-aged men and women with comorbid coronary heart disease and depression (the British Whitehall-II study), and May et al. (2017) found, using a large cohort of patients who underwent angiography (aged $\geq 18$ ), that a depression diagnosis at any time following coronary artery disease diagnosis was the strongest predictor of all-cause death, emphasizing the need for continual screening of depression among patients with heart diseases.

The prevalence of anxiety/depression is significantly higher in patients with comorbid conditions than in the general population (Husaini et al., 2004; PearsonSttuttard et al., 2019; Roy-Byrne et al., 2008), and the combination is associated with poorer health outcomes. These observations are generalizable across a variety of populations, including the United States (Li et al., 2019; Voinov et al., 2013). There is also, on an almost global basis, a higher prevalence of preexisting comorbidities and poorer health outcomes among men compared to women (Rovito et al., 2017; World Health Organization Regional Office for Europe, 2018). It is no longer tenable to assert that inequitable burden of poor health experienced by men is the consequence of failure to use health services (Schlichthorst et al., 2016). One possible explanation may relate to the markedly lower frequency with which depression is diagnosed in men (World Health Organization, 2019), possibly because of the failure to recognize a "male type" presentation typified by somatization of symptoms, irritability, anger, and substance abuse (Martin et al., 2013). Effective management of depression has long been shown to reduce primary care visit frequency and costs (Simon et al., 2001). It is also clear that an optimal outcome for chronic conditions occurs when comorbid depression and/or anxiety is recognized and effectively managed (Atlantis et al., 2013; Bhattacharya et al., 2016; DeJean et al., 2013; Tully \& Baumeister, 2015). The implication of these data is that to reduce the disproportionate burden of poor health among men, a focus on strategies to efficiently recognize and manage multiple concurrent chronic diseases with a low threshold to consider depression and anxiety, particularly in men who are frequent users of health care, is required.

The major strength of the MAILES study is its valueadded benefit of combining selected participants from two high-quality cohort studies to provide a wealth of measured and self-reported information about multiple chronic conditions, together with the data collected on a wide range of biomedical and sociodemographic variables as well as linked information about primary health service utilization from Medicare data. The MAILES study has a sound epidemiological base, a comparatively large sample of randomly selected community-dwelling men, and a high overall response rate, allowing its findings to be generalized to the broader population (Grant et al., 2014). As with most cohort studies, the key limitation of the MAILES study is its reliance on self-reported information for some lifestyle and medical factors, such as rheumatic diseases (Gill \& Hill, 2017). However, De-Loyde et al. (2015) reported that the use of patient self-reported questionnaires to ascertain comorbid conditions remains a valid method for health services research, as shown in the sensitivity analyses, which indicated the same conclusion for using clinically diagnosed or medication-based anxiety and depression. Moreover, self-reports of cardiac and stroke events have been reported to be accurate (Bergmann et al., 1998; Kriegsman et al., 1996). There is accumulating evidence for a malespecific phenotype of depression (e.g., increased anger and risk-taking) that is not captured by the BDI or CESD. The use of specific questionnaires such as the Male Depression Risk Scale-22 (MDRS-22; Rice et al., 2013, 2018) provides a better understanding depression (and anxiety) in men and associated service use in men. Another limitation of the study is the lack of information on the severity of the disease and type of treatment. Although the study participants were representative of its target population, they were also predominantly Caucasian, aged 35-80 years (at recruitment), and community-dwelling (Grant et al., 2014). Also, the BDI, CES-D, and GAD-7 are not formal clinical diagnostic assessments for depression or anxiety. This point should be considered when interpreting the results that are based on the use of screening instruments. 


\section{Conclusions}

Our study strengthens the evidence-based information about the nature of multimorbidity in men and its impact on primary health services use, which is critical to inform guidelines and health management for effective and efficient care of men with multimorbidity and comorbid anxiety and/or depression. Coexisting conditions may also influence the effectiveness of therapies or modify patients' priorities concerning their health care (Boyd et al., 2011). Effective management of this patient group thus requires effective management of other comorbid conditions as well (Boult, 2010; Caughey \& Roughead, 2011), bearing on the different patterns in men's health service use (Smith et al., 2006). More importantly, multimorbidity patterns involving CVD should be considered in the development of clinical trials and guidelines to better inform medical decision-making and provide comprehensive or collaborative care for patients with CVD and comorbid conditions including anxiety and/or depression (Assari et al., 2013; Boyd et al., 2011; Glynn et al., 2008; Morgan et al., 2009).

\section{Acknowledgments}

The authors are most grateful for the generosity of the cohort participants in giving their time and effort to the study. The study team is also very appreciative of the work of the clinic, recruiting, and research support staff for their substantial contribution to the success of the study.

\section{Declaration of Conflicting Interests}

The author(s) declared the following potential conflicts of interest with respect to the research, authorship, and/or publication of this article: GW reports grants from Bayer Schering, grants from Eli Lilly, grants from Lawley Pharmaceuticals, nonfinancial support from Eli Lilly, nonfinancial support from Novo Nordisk, personal fees from Bayer Schering, personal fees from Eli Lilly, personal fees from Sanofi, personal fees from Novo Nordisk, personal fees from AstraZeneca, personal fees from I-Nova, personal fees from Elsevier, outside the submitted work. All other authors have no declarations.

\section{Funding}

The author(s) disclosed receipt of the following financial support for the research, authorship, and/or publication of this article: This work was funded through the Australian National Health and Medical Research Council (Project Grant \#627227) and The Hospital Research Foundation (Woodville, SA, Australia) Research Grant. The funding sources had no role in the design and conduct of the study; collection, management, analysis, or interpretation of the data; or preparation, review, or approval of the manuscript.

\section{Ethical Approval and Consent to Participate}

All protocols were approved by the Royal Adelaide Hospital and the Queen Elizabeth Hospital Research Ethics Committees, with written, informed consent obtained from all participants.

\section{ORCID iD}

Shu-Kay Ng iD https://orcid.org/0000-0002-6865-9384

\section{Supplemental Material}

Supplemental material for this article is available online.

\section{References}

Academy of Medical Sciences. (2018). Multimorbidity: A priority for global health research. The Academy of Medical Sciences.

Assari, S., Lankarani, M. M., \& Ahmadi, K. (2013). Comorbidity influences multiple aspects of well-being of patients with ischemic heart disease. International Cardiovascular Research Journal, 7, 118-123.

Atlantis, E., Fahey, P., Cochrane, B., \& Smith, S. (2013). Bidirectional associations between clinically relevant depression or anxiety and COPD: A systematic review and meta-analysis. Chest, 144, 766-777.

Atlantis, E., Lange, K., Goldney, R. D., Martin, S., Haren, M. T., Taylor, A., O’Loughlin, P. D., Marshall, V., Tilley, W., \& Wittert, G. A. (2011). Specific medical conditions associated with clinically significant depressive symptoms in men. Social Psychiatry and Psychiatric Epidemiology, 46, 1303-1312.

Atlantis, E., Shi, Z., Penninx, B. J. W. H., Wittert, G. A., Taylor, A., \& Almeida, O. P. (2012). Chronic medical conditions mediate the association between depression and cardiovascular disease mortality. Social Psychiatry and Psychiatric Epidemiology, 47, 615-625.

Australian Institute of Health and Welfare. (2015). Health expenditure Australia 2013-14. Health and welfare expenditure series no. 54. Cat. no. HWE 63. AIHW.

Batstra, L., Bos, E. H., \& Neeleman, J. (2002). Quantifying psychiatric comorbidity: Lessions from chronic disease epidemiology. Social Psychiatry and Psychiatric Epidemiology, 37, 105-111.

Baty, F., Putora, P. M., Isenring, B., Blum, T., \& Brutsche, M. (2013). Comorbidities and burden of COPD: A population based case-control study. PLoS One, 8, e63285.

Beck, A. T., \& Beck, R. W. (1972). Screening depressed patients in family practice. Postgraduate Medicine, 52, 81-85.

Benjamini, Y., \& Hochberg, Y. (1995). Controlling the false discovery rate: A practical and powerful approach to multiple testing. Journal of the Royal Statistical Society Series $B, 57,289-300$.

Bergmann, M. M., Byers, T., Freedman, D. S., \& Mokdad, A. (1998). Validity of self-reported diagnoses leading to hospitalization: A comparison of self-reports with hospital records in a prospective study of American adults. American Journal of Epidemiology, 147, 969-977.

Bhattacharya, R., Shen, C., Wachholtz, A. B., Dwibedi, N., \& Sambamoorthi, U. (2016). Depression treatment decreases healthcare expenditures among working age patients with comorbid conditions and type 2 diabetes mellitus along with newly-diagnosed depression. BMC Psychiatry, 16, 247.

Billett, J., Cowie, M. R., Gatzoulis, M. A., Vonder Muhll, I. F., \& Majeed, A. (2008). Comorbidity, healthcare utilisation and process of care measures in patients with congenital 
heart disease in the UK: Cross-sectional, population-based study with case-control analysis. Heart, 94, 1194-1199.

Boult, C. (2010). Interdisciplinary primary care for patients with heart disease and several co-morbid conditions. Cardiology, 117, 7.

Boyd, C. M., Leff, B., Wolff, J. L., Yu, Q., Zhou, J., Rand, C., \& Weiss, C. O. (2011). Informing clinical practice guideline development and implementation: Prevalence of coexisting conditions among adults with coronary heart disease. Journal of the American Geriatrics Society, 59, 797-805.

Burgess, P. M., Pirkis, J. E., Slade, T. N., Johnston, A. K., Meadows, G. N., \& Gunn, J. M. (2009). Service use for mental health problems: Findings from the 2007 National Survey of Mental Health and Wellbeing. Australian and New Zealand Journal of Psychiatry, 43, 615-623.

Caughey, G. E., \& Roughead, E. E. (2011). Multimorbidity research challenges: Where to go from here? Journal of Comorbidity, 1, 8-10.

DeJean, D., Giacomini, M., Vanstone, M., \& Brundisini, F. (2013). Patient experiences of depression and anxiety with chronic disease: A systematic review and qualitative metasynthesis. Ontario Health Technology Assessment Series, $13,1-33$.

De-Loyde, K. J., Harrison, J. D., Durcinoska, I., Shepherd, H. L., Solomon, M. J., \& Young, J. M. (2015). Which information source is best? Concordance between patient report, clinician report and medical records of patient co-morbidity and adjuvant therapy health information. Journal of Evaluation in Clinical Practice, 21, 339-346.

Feinstein, A. R. (1967). Clinical Judgment. Williams and Wilkins.

Fortin, M., Lapointe, L., Hudon, C., Vanasse, A., Ntetu, A. L., \& Maltais, D. (2004). Multimorbidity and quality of life in primary care: A systematic review. Health and Quality of Life Outcomes, 2, 51.

Gallo, J. J. (2017). Multimorbidity and mental health. American Journal of Geriatric Psychiatry, 25, 520-521.

Gill, T. K., \& Hill, C. L. (2017). The accuracy of self-report in rheumatic diseases. Journal of Rheumatology, 44, 1109-1111.

Glynn, L. G., Buckley, B., Reddan, D., Newell, J., Hinde, J., Dinneen, S. F., \& Murphy, A. W. (2008). Multimorbidity and risk among patients with established cardiovascular disease: A cohort study. British Journal of General Practice, 58, 488-494.

Grant, J. F., Martin, S. A., Taylor, A. W., Wilson, D. H., Araujo, A., Adams, R. J. T., Jenkins, A., Milne, R. W., Hugo, G. J., Atlantis, E., \& Wittert, G. A. (2014). Cohort profile: The Men Androgen Inflammation Lifestyle Environment and Stress (MAILES) Study. International Journal of Epidemiology, 43, 1040-1053.

Harrison, C., \& Siriwardena, A. N. (2018). Editorial multimorbidity. Australian Journal of General Practice, 47, 6-7.

Husaini, B. A., Hull, P. C., Sherkat, D. E., Emerson, J. S., Overton, M. T., Craun, C., Cain, V. A., \& Levine, R. S. (2004). Diabetes, depression, and healthcare utilization among African Americans in primary care. Journal of the National Medical Association, 96, 476-484.

Jones, P. D., Seoane, L., Deichmann Jr, R., \& Kantrow, C. (2011). Differences and similarities in the practice of medicine between Australia and the United States of America: Challenges and opportunities for the University of Queensland and the Ochsner Clinical School. Ochsner Journal, 11, 253-258.

Kriegsman, D. M., Penninx, B. W., van Eijk, J. T., Boeke, A. J., \& Deeg, D. J. (1996). Self-reports and general practitioner information on the presence of chronic diseases in community dwelling elderly: A study on the accuracy of patients' self-reports and on determinants of inaccuracy. Journal of Clinical Epidemiology, 49, 1407-1417.

Lancet editorial. (2018). Making more of multimorbidity: An emerging priority. Lancet, 391, 1637.

Li, H., Ge, S., Greene, B., \& Dunbar-Jacob, J. (2019). Depression in the context of chronic diseases in the United States and China. International Journal of Nursing Sciences, 6, $117-122$.

Mair, F. S., \& Gallacher, K. I. (2017). Multimorbidity: What next? British Journal of General Practice, 67, 248-249.

Martin, L. A., Neighbors, H. W., \& Griffith, D. M. (2013). The experience of symptoms of depression in men vs women. JAMA Psychiatry, 70, 1100-1106.

Masnoon, N., Shakib, S., Kalisch-Ellett, L., \& Caughey, G. E. (2017). What is polypharmacy? A systematic review of definitions. BMC Geriatrics, 17, 230.

May, H. T., Horne, B. D., Knight, S., Knowlton, K. U., Bair, T. L., Lappe, D. L., Le, V. T., \& Muhlestein, J. B. (2017). The association of depression at any time to the risk of death following coronary artery disease diagnosis. European Heart Journal - Quality of Care and Clinical Outcomes, 3, 296-302.

McRae, I., Yen, L., Jeon, Y. H., Herath, P. M., \& Essue, B. (2013). Multimorbidity is associated with higher out-ofpocket spending: A study of older Australians with multiple chronic conditions. Australian Journal of Primary Health, 19, 144-149.

Milton, J. C., Hill-Smith, I., \& Jackson, S. H. D. (2008). Prescribing for older people. British Medical Journal, 336, 606-609.

Morgan, M., Dunbar, J., Reddy, P., Coates, M., \& Leahy, R. (2009). The TrueBlue study: Is practice nurse-led collaborative care effective in the management of depression for patients with heart disease or diabetes? BMC Family Practice, 10, 46.

Nabi, H., Shipley, M. J., Vahtera, J., Hall, M., Korkeila, J., Marmot, M. G., Kivimaki, M., \& Singh-Manoux, A. (2010). Effects of depressive symptoms and coronary heart disease and their interactive associations on mortality in middle-aged adults: The Whitehall II cohort study. Heart, 96, 1645-1650.

Navickas, R., Petric, V. K., Feigl, A. B., \& Seychell, M. (2016). Multimorbidity: What do we know? What should we do? Journal of Comorbidity, 6, 4-11.

$\mathrm{Ng}$, S. K. (2015). A two-way clustering framework to identify disparities in multimorbidity patterns of mental and 
physical health conditions among Australians. Statistics in Medicine, 34, 3444-3460.

Ng, S. K., Holden, L., \& Sun, J. (2012). Identifying comorbidity patterns of health conditions via cluster analysis of pairwise concordance statistics. Statistics in Medicine, 31, 3393-3405.

Ng, S. K., Tawiah, R., \& McLachlan, G. J. (2019). Unsupervised pattern recognition of mixed data structures with numerical and categorical features using a mixture regression modelling framework. Pattern Recognition, 88, 261-271.

Ng, S. K., Tawiah, R., Sawyer, M., \& Scuffham, P. (2018). Patterns of multimorbid health conditions: A systematic review of analytical methods and comparison analysis. International Journal of Epidemiology, 47, 1687-1704.

Nishtala, P. S., Narayan, S. W., Wang, T., \& Hilmer, S. N. (2014). Associations of drug burden index with falls, general practitioner visits, and mortality in older people. Pharmacoepidemiology and Drug Safety, 23, 753-758.

Nunes, B. P., Flores, T. R., Mielke, G. I., Thume, E., \& Facchini, L. A. (2016). Multimorbidity and mortality in older adults: A systematic review and meta-analysis. Archives of Gerontology and Geriatrics, 67, 130-138.

Pearson-Stuttard, J., Ezzati, M., \& Gregg, E. W. (2019). Multimorbidity - a defining challenge for health systems. Lancet Public Health, 4, e599-e600.

Prados-Torres, A., Calderon-Larranaga, A., Hancco-Saavedra, J., Poblador-Plou, B., \& van den Akker, M. (2014). Multimorbidity patterns: A systematic review. Journal of Clinical Epidemiology, 67, 254-266.

Radloff, L. S. (1977). The CES-D scale: A self-report depression scale for research in the general population. Applied Psychological Measurement, 1, 385-401.

Rice, S. M., Fallon, B. J., Aucote, H. M., \& Moller-Leimkuhler, A. M. (2013). Development and preliminary validation of the male depression risk scale: Furthering the assessment of depression in men. Journal of Affective Disorders, 151, 950-958.

Rice, S. M., Oliffe, J. L., Kelly, M. T., Cormie, P., Chambers, S., Ogrodniczuk, J. S., \& Kealy, D. (2018). Depression and prostate cancer: Examining comorbidity and malespecific symptoms. American Journal of Men's Health, 12, 1864-1872.

Robertson, J., McElduff, P., Pearson, S. A., Henry, D. A., Inder, K. J., \& Attia, J. R. (2012). The health services burden of heart failure: An analysis using linked population health data-sets. BMC Health Services Research, 12, 103.

Rovito, M. J., Leonard, B., Llamas, R., Leone, J. E., Talton, W., Fadich, A., \& Baker, P. (2017). A call for gender-inclusive global health strategies. American Journal of Men's Health, 11, 1804-1808.

Roy-Byrne, P. P., Davidson, K. W., Kessler, R. C., Asmundson, G. J., Goodwin, R. D., Kubzansky, L., Lydiard, R. B., Massie, M. J., Katon, W., Laden, S. K., \& Stein, M. B. (2008). Anxiety disorders and comorbid medical illness. General Hospital Psychiatry, 30, 208-225.

Salisbury, C., Johnson, L., Purdy, S., Valderas, J. M., \& Montgomery, A. A. (2011). Epidemiology and impact of multimorbidity in primary care: A retrospective cohort study. British Journal of General Practice, 61, e12-e21.

Schafer, I., Hansen, H., Schon, G., Hofels, S., Altiner, A., Dahlhaus, A., Gensichen, J., Riedel-Heller, S., Weyerer, S., Blank, W. A., Konig, H. H., von dem Knesebeck, O., Wegscheider, K., Scherer, M., van den Bussche, H., \& Wiese, B. (2012). The influence of age, gender and socioeconomic status on multimorbidity patterns in primary care. First results from the multicare cohort study. BMC Health Services Research, 12, 89.

Schlichthorst, M., Sanci, L. A., Pirkis, J., Spittal, M. J., \& Hocking, J. S. (2016). Why do men go to the doctor? Sociodemographic and lifestyle factors associated with healthcare utilisation among a cohort of Australian men. BMC Public Health, 16, 1028.

Shafer, A. B. (2006). Meta-analysis of the factor structures of four depression questionnaires: Beck, CES-D, Hamilton, and Zung. Journal of Clinical Psychology, 62, 123-146.

Simon, G. E., Manning, W. G., Katzelnick, D. J., Pearson, S. D., Henk, H. J., \& Helstad, C. P. (2001). Cost-effectiveness of systematic depression treatment for high utilizers of general medical care. Archives of General Psychiatry, 58, 181-187.

Singer, L., Green, M., Rowe, F., Ben-Shlomo, Y., \& Morrissey, K. (2019). Social determinants of multimorbidity and multiple functional limitations among the ageing population of England, 2002-2015. SSM - Population Health, 8, 100413.

Smith, J. A., Braunack-Mayer, A., \& Wittert, G. (2006). What do we know about men's help-seeking and health service use? Medical Journal of Australia, 184, 81-83.

Smith, S. M., Wallace, E., O'Dowd, T., \& Fortin, M. (2016). Interventions for improving outcomes in patients with multimorbidity in primary care and community settings. Cochrane Database of Systematic Reviews, 3, CD006560.

Spitzer, R. L., Kroenke, K., Williams, J. B., \& Lowe, B. (2006). A brief measure for assessing generalized anxiety disorder: The GAD-7. Archives of Internal Medicine, 166, 1092-1097.

Tully, P. J., \& Baumeister, H. (2015). Collaborative care for comorbid depression and coronary heart disease: A systematic review and meta-analysis of randomised controlled trials. BMJ Open, 5, e009128

Vamos, E. P., Mucsi, I., Keszei, A., Kopp, M. S., \& Novak, M. (2009). Comorbid depression is associated with increased healthcare utilization and lost productivity in persons with diabetes: A large nationally representative Hungarian population survey. Psychosomatic Medicine, 71, 501-507.

Van der Kooy, K., van Hout, H., Marwijk, H., Marten, H., Stehouwer, C., \& Beekman, A. (2007). Depression and the risk for cardiovascular diseases: Systematic review and meta analysis. International Journal of Geriatric Psychiatry, 22, 613-626.

Vogeli, C., Shields, A. E., Lee, T. A., Gibson, T. B., Marder, W. D., Weiss, K. B., \& Blumenthal, D. (2007). Multiple chronic conditions: Prevalence, health consequences, and implications for quality, care management and costs. Journal of General Internal Medicine, 22(Suppl 3), 391-395. 
Voinov, B., Richie, W. D., \& Bailey, R. K. (2013). Depression and chronic diseases: It is time for a synergistic mental health and primary care approach. Primary Care Companion for CNS Disorders, 15, PCC.12r01468.

Weinberg, C. R. (1993). Toward a clearer definition of confounding. American Journal of Epidemiology, 137, 1-8.

Westert, G. P., Satariano, W. A., Schellevis, F. G., \& van den Bos, G. A. M. (2001). Patterns of comorbidity and the use of health services in the Dutch population. European Journal of Public Health, 11, 365-372.

Wittert, G., Martin, S., Adams, R., Taylor, A., Wilson, D., \& Araujo, A. (2011). Socioeconomic, demographic, lifestyle and health related factors, and use of general practice services by South Australian Men [Conference session]. State Population Health Conference, Adelaide, October 2011. Public Health Association Australia.
World Health Organization. (2016). Multimorbidity: Technical series on safer primary care. World Health Organization. Licence: CC BY-NC-SA 3.0 IGO.

World Health Organization. (2019). World Health Statistics 2019: Monitoring health for the sustainable development goals (SDGs). World Health Organization.

World Health Organization Regional Office for Europe. (2018). The health and well-being of men in the WHO European Region: Better health through a gender approach. WHO Regional Office for Europe.

Zulman, D. M., Chee, C. P., Wagner, T. H., Yoon, J., Cohen, D. M., Holmes, T. H., Ritchie, C., \& Asch, S. M. (2015). Multimorbidity and healthcare utilization among high-cost patients in the US Veterans Affairs Health Care System. BMJ Open, 5, e007771. 